\title{
Resonance of Cultural Tourism: Introduction to the Special Issue
}

\author{
Irena Weber \\ Guest Editor \\ University of Primorska, Faculty of Tourism Studies - Turistica, Slovenia \\ irena.weber@fts.upr.si
}

https://doi.org/10.26493/2335-4194.11.99-10o

\begin{abstract}
Tourism education and the industry have much to offer each other, but education's contribution must ultimately be rooted in cultivating students' capacities to question, to critique, to relate, and to engage with the tourism world from a standpoint of values and convictions honed through thoughtful consideration and exposure to the perspectives of others. The development of practical vocational competencies must be pursued in dialogue with, rather than ahead or in place of, humanistic capacities. Otherwise, we may find ourselves to be very efficiently producing a world that is not of the shape we want at all. (Caton, 2014)
\end{abstract}

At one of the regular meetings of the Department of Cultural Tourism at the Faculty of Tourism Studies - Turistica, the idea was floated that a special issue of Academica Turistica could produce a body of work that could be used, among others, to support teaching in the newly established undergraduate programme of Cultural tourism.

Several preliminary discussions of the various topics researched by the members of the Department indicated that to produce a comprehensive work on the subject of cultural tourism as a rounded teaching material would be a tall order indeed. However, tying up individual researchers' interests in a meaningful dialogue that may hopefully resonate among the members of the Department, the students and the network of colleagues at other education and research institutions working in the same or similar areas appeared more feasible. Eventually, on a rather short notice, the call for papers was extended through personal networks inviting foreign colleagues to contribute their research to this special issue of Academica Turistica on 'Resonance of Cultural Tourism,' expanding thus local resonance to multiple localities with good vibrations.

At its core, resonance is a quality of evoking response. This pertains to both material and symbolic aspects of embodiment, communication, spatial orientation and relational practices. In a phenomenological sense, resonance refers to everyday cultural tourism encounters that vibrate within the timespace of material and symbolic exchange, of 'Being-in-theworld' and the co-production of sense and meaning. The widest framework for the special issue was the understanding that cultural tourism should not be treated as merely one of the adjective tourisms. Culture in cultural tourism was understood holistically as a complexity of knowledge, beliefs, arts, morals, law, customs, capabilities and habits found from Tyler on in numerous permutations of a definition. The other framework was a clear notion of an existing split in tourism studies between business oriented and social science and humanities oriented research and teaching, with the business side occupying a much larger portion of the field which renders the empowerment of humanities approach rather imperative in order to address the immense disparity. The present slim volume represents a small attempt in this direction with seven papers that are predominantly based on original fieldwork and supported by qualitative methodology.

The first review paper on 'Cultural Tourism from an Academic Perspective' by Tina Orel Frank and Zorana Medarić aptly demonstates the complexity of 
contemporary dilemmas in defining both culture and tourism that ultimately calls for more epistemological work on cultural tourism in the future. The notion of a resonance is directly addressed in the research note by Emilio Cocco who specializes inter alia in maritime sociology and the Mediterranean. His preliminary take on his new research in Odessa is grounded in the concept of contemporary interpretations of cosmopolitanism and his innovative approaches to sea/land relationships in various tourism destinations with an emphasis on port cities. Looking at the traumatic relationship between Germany and the Jewish diaspora, Anne M. Blankenship roots her research in anthropological frames of secular pilgrimage and the concept of repentance to show how Jewish tourists experience Berlin and how Berlin is addressing the Holocaust through various memorials and topical guided tours. Switching to another city across the sea, Indianapolis, our colleagues Yao-Yi Fu, Suosheng Wang, Carina King, and Yung-Tsen Chu tackled 'The Influence of an International Festival on Visitors' Attitudes toward Diverse Cultures' by measuring visitation frequency, stay-time at the event, similar event participation, cultural interest, and overseas travel experience contributing to any observed differences in visitors' attitudes. Their work represents an effort towards a potential longitudinal study that addresses cultural diversity in a productive, quantifiable way. Bourdieu's cultural capital underlines a field study of the art of tea by Irena Weber in the mainland China and Taiwan in the form of tea houses, specialized tea museums, tea trails, guided tours, and tea tastings. A research note by a young researcher Helena Tolić, 'Anthropological Portrait of a Home Turned Into a Tourist Resource,' testifies to the sound Croatian tradition of anthropological research and teaching in providing an example of doing anthropology at home with the aim to tackle the comparatively valuable case of transformative and contested contemporary tourism processes. Home in a sense of the location is also the topic of the linguistic analysis 'The Interplay between the Verbal and Visual in Outdoor Interpretive Panels' by Šarolta Godnič Vičič, Nina Lovec and Ljudmila Sinkovič that employs the Barthesian semiotic approach of the relationship between the textual and the visual within the context of cultural heritage from the perspective of contemporary linguistics.

Last but not least the cover photograph depicts a detail of a mobile shown at the first Ars Turistica exhibition that took place in 2017 in front of the Faculty of Tourism Studies - Turistica. It was the results of the Art and Tourism class, where Slovenian and Erasmus exchange students were engaged in a creative dialogue involving land art, kinetic sculpture, contemporary tourism, mobility and sustainability. Walt Whitman's stance from his Song of the Open Road forms a spiral in the middle. Whitman, after being done with indoor complaints, libraries, querulous criticisms, took to the open road not to get rid of everyone, on the contrary, to meet the less fortunate, the marginal, the forgotten, to extend the hand to another traveler, much in the same way as the great Slovenian poet of the open road and marginality, Frane Milčinski Ježek, who saw that all roads, however crisscrossed, ultimately lead to another human being that should not be overlooked or forgotten. Without the open road and the stretched hand, what shape is our (tourist) world after all?

\section{References}

Caton, K. (2014). Underdisciplinarity: Where are the humanities in tourism education? Journal of Hospitality, Leisure, Sport \& Tourism Education, 15, 24-33.

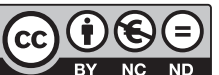

This paper is published under the terms of the Attribution- NonCommercial-NoDerivatives 4.0 International (CC B Y-NC-ND 4.0) License. 